\title{
Fabrication and Working of a Compressed Air Vehicle
}

\author{
Sampath S. Salins ${ }^{1}$, Asrar Ali Khan ${ }^{2}$, Khaled Riyaz ${ }^{2}$, Ismail Mahmoud ${ }^{2}$, Syed Naeem ${ }^{2}$, Krishnamurthy H. \\ Sachidananda ${ }^{1^{*}}$ \\ ${ }^{1}$ School of Engineering and IT, Manipal Academy of Higher Education, Dubai 345050, UAE \\ ${ }^{2}$ Department of Mechanical Engineering, Manipal Academy of Higher Education, Dubai 345050, UAE
}

Corresponding Author Email: sachidananda@manipaldubai.com

https://doi.org/10.18280/jesa.540111

Received: 30 August 2020

Accepted: 4 January 2021

\section{Keywords:}

compressed air vehicle, pneumatic rotary

engine, compressor, sustainable energy

\begin{abstract}
The automotive industries are looking for many ways in order to reduce the weight of the vehicle. Also, light vehicles are better at handling and also efficiency of the vehicle is more. Heavy weighted vehicles as compared to light weighted vehicles produce a large amount of harmful gases like $\mathrm{CO}_{2}$ and $\mathrm{SO}_{2}$. There are many alternatives in order to reduce these harmful gases. One such alternative is using compressed air to power the vehicle. So, in this research work the main aim of the project is to design, fabricate and test a single seated vehicle that runs on an alternative source of energy, specifically compressed air. A pneumatic rotary engine having a maximum pressure of $7 \mathrm{bar}$ is used in designing the above air compressed vehicle. In order to achieve speed of 30-40 Km/hr, two air cylinders are used in this design. From this study it can be concluded that using less dense and higher volume tank it is possible to increase the output velocity of the vehicle. The findings of this research can be used for further development of air compressed vehicle.
\end{abstract}

\section{INTRODUCTION}

Compressed air car is one of the future modes of transportation, which is powered by a motor, running on compressed air. The first air-powered vehicles were commonly used in trains. The Mekarski air engine, the pneumatic system was used to power locomotives in the 1800 's. There have been many inventions of the air car starting from 1896. Most recently, Tata motors introduced the MDI CityCat as the first commercial air car.

One of the major sources of air pollution is caused due to automobile running on the road. Also, it is a known fact that petroleum resources may be depleted in the future. Gasoline, which has been the main source of fuel for cars, produces carbon monoxide, nitrogen oxides and unburned hydrocarbons are the main source of pollutants causing pollution. Hence, due to above problems alternative fuels needs to be considered. One such alternative fuel that can be used in order to power vehicles is compressed air. An air engine, using compressed air, which is stored in a compressed air tank is used to power compressed air vehicle. So, during the initial stages they used a 150 -cc bike engine and used compressed air in order to power this engine. But, due to negligible output, a pneumatic motor replaced the engine. The pneumatic motor is connected to a tank filled with compressed air, which runs the motor thereby resulting in mechanical work done, which is the movement of the drive shaft. Based on compressed air vehicle many research works have been done and some of the literature corresponding to them is presented.

Papson et al. [1] has studied and presented the analysis and performance as well as environmental impacts of a compressed air vehicle (CAV). He used pneumatic motor and onboard high-pressure gas tanks in order to perform this analysis. They concluded that the major drawback observed from this analysis is that CAV's have a limited driving range. Kumar et al. [2] in their research work discussed about the design and manufacturing of a pneumatic vehicle. The main aim of this work was to design a vehicle that would use other sources of energy rather than fuel in order to power the car. They concluded that this research work is eco-friendly and does not pollute the atmosphere as compared to the standard internal combustion engines. It also focuses on using atmospheric air as the main source of fuel. Ingle et al. [3] presented a review paper on the compressed air vehicle. In this review they discussed about the 3- wheeler vehicle using air motor. From this paper it is concluded that the compressed air vehicles are pollution free, economical and more efficient means of transportation.

Pathak et al. [4] presented a review on compressed air vehicle. They considered light weighted vehicles which runs on compressed air are discussed in detail. Vane type novel air turbine is used and tested for this application. From this work it is concluded that the air turbine gives more efficiency as compared to the conventional IC engine. Rixon et al. [5] presented a paper on fabrication of air-compressed bike which uses compressed air. They used a turbine in order to run the engine as compared to normal piston engine. The turbine employed converts the pneumatic energy of compressed air into mechanical work and in turn efficiency can be boosted with the help of an air pressure amplifier and shock absorber connected to the tank. This paper also discusses how this technology can be implemented into hybrids for cost effective design.

Singh [6] has modified a 4-stroke engine into a 2-stroke engine which is powered by a tank filled with compressed air. $\mathrm{He}$ discussed theoretical advantages of a compressed air engine and how to overcome the inefficiency and leakages of the components. Allam and Zakaria [7] have studied 
experimentally the performance of an air engine. They used a single cylinder petrol engine and tested this engine when it is running with gasoline and they converted this engine to run on compressed air in order to measure the performance. They concluded that compressed air vehicle is one of the best technologies to be utilized as it is ecofriendly as well as air is freely available. Shetty et al. [8] presented a paper on the design and construction of an air powered quad bike, which serves as a solution to reduce atmospheric pollution. The paper discusses the different observation obtained from the analysis of the quad bike and they studied the relation between torque and brake power, indicated power and mean effective pressure. The tank used was able to run the bike only for a limited amount of time. They concluded by giving additional information on how the quad bike can be optimized. Purushothaman et al. [9] presented a paper on the design and development of compressed air engine using a modified IC engine. From this paper they concluded that the brake power and mechanical efficiency are found to be in the acceptable limit. Tandan et al. [10] presented a review paper on study and development of compressed air engine and its power source. They used compressed air as an alternative form of energy in a four-stroke bike and explained the working of single energy engine and dual energy engine. From this paper it can be concluded that with stress analysis and thermodynamic analysis, the losses in energy and efficiency can be further minimized. Verma [11] studied the latest developments in air compressed vehicles. This research paper gives a well detailed explanation of the merits and demerits of the vehicle as well as solution to the problems the vehicle faces in the market. Even though there has been no significant improvement in the development and production of the air car, it is still a topic of interest due to its large economical and cost benefits. Kumar et al. [12] experimentally studied the performance of the air powered car by changing the cam and values of the IC engine. This paper discusses the various tests done and graphs by comparing the torque verses other mechanical factors of the vehicle. From the results obtained they concluded that it is possible to build a vehicle emitting zero pollution, being highly efficient at low pressures, and providing us with an ecofriendly form of transport.

Most of the work on air compressed vehicle has been done on a 4 stroke Internal combustion bike engine converted to a 2 stroke Internal combustion engine. Usually, in case of 4 stroke IC engines, it was observed that the engine couldn't provide enough torque when it is subjected to heavier loads [13-15]. Also, the mileage and speeds were low [16, 17]. This drawback can be improved by using pneumatic rotary vane motor. In this research work we have attempted to design and fabricate a compressed air vehicle by using a pneumatic motor. The compressed air vehicle has been completely designed using ANSYS for the different boundary conditions of the chassis and the actual model have been constructed and tested to check its performance with respect to mileage and speed. The experiments were conducted on this developed model considering air pressure and checked for performance.

\section{METHODOLOGY}

From Figure 1, the process that was followed in order to build compressed air vehicle started off with defining the problem, and the problem being how to run a vehicle purely on compressed air. Initially after understanding the basic principle of a compressed air technology considering the literature review, the design and analysis of the different parts of the vehicle needs to be analyzed. The design of the chassis has been drawn and analyzed using ANSYS. Then the process of procurement of the material for the construction of the vehicle have been performed. Cutting, grinding, welding and assembly of the different components as per the design specifications have been performed. The vehicle assembled after fabrication is tested for maximum velocity under different air pressures and values have been noted.

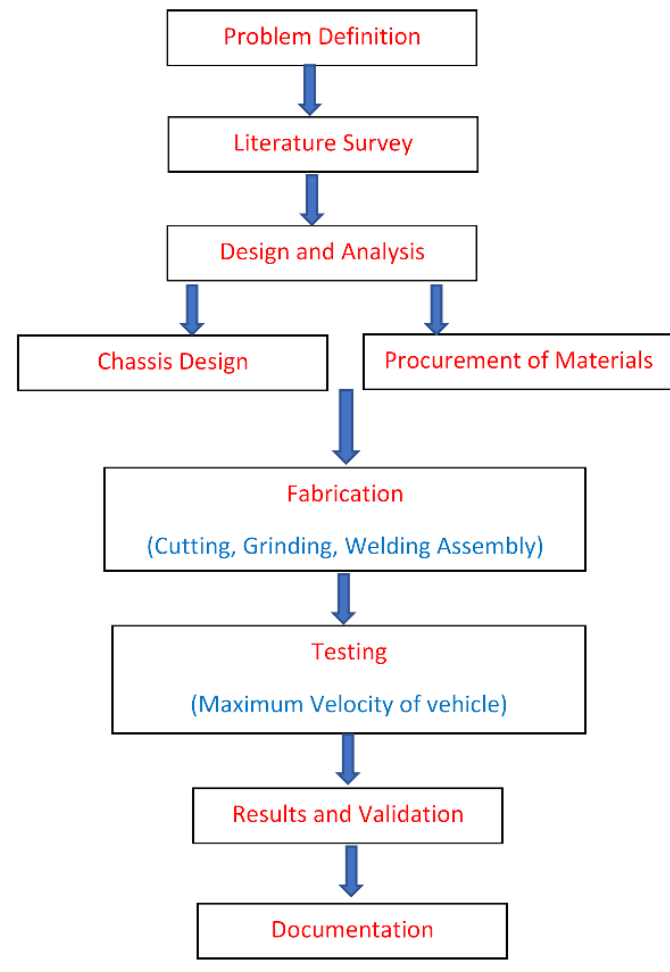

Figure 1. Methodology process flowchart for the fabrication of a Compressed Air Vehicle

\section{DESIGN AND ANALYSIS OF CHASSIS}

This section discusses the design and analysis of the chassis of the compressed air vehicle [18]. Initially the chassis of the vehicle have been designed by considering various parameters such as driver comfortability and the specific dimensions of the vehicle. Then this dimension has been converted into 3dimensional drawing using Creo software (Refer Figure 2). The measurements of the chassis were manually recorded using measuring tape and the diameters of the pipes were recorded by using vernier caliper so that the design of the chassis is as per the dimensions planned. Then, the static structural analysis of the chassis was done using the software ANSYS Workbench. From the results of the analysis, it was found that the factor of safety recorded was found to be greater than 1 .

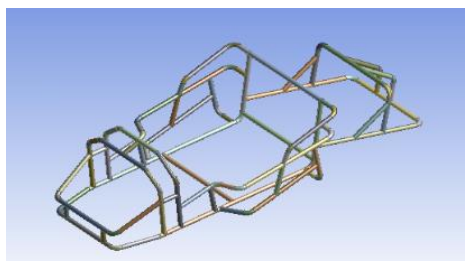

Figure 2. Three - Dimensional model of the chassis 
Figure 3 is the static rigid structure of the chassis which have been constructed to analyze whether this structure is able to withstand different forces during actual testing of the vehicle. From this static rigid structure, it is possible to find the force distribution acting on the chassis. The corresponding boundary conditions set for conducting the side impact test and the analysis have been carried out using ANSYS 9. The representation of the arrows in the diagram shows the applied force of $138.88 \mathrm{~N}$ and the links opposite to where the force is applied is considered as fixed support. By fixing and applying the specified load, the total deformation as observed from Figure 4 was recorded. From this numerical result it is observed that the total deformation for the applied load was found to be $0.9352 \mathrm{~mm}$ (Maximum) and is within the safe zone of working. Also, the maximum equivalent stress was checked for the same force and from Figure 5 it is observed that the maximum equivalent stress was found to be $134.3 \mathrm{MPa}$. The zone of maximum equivalent stress can be observed as red portion in case of Figure 5.

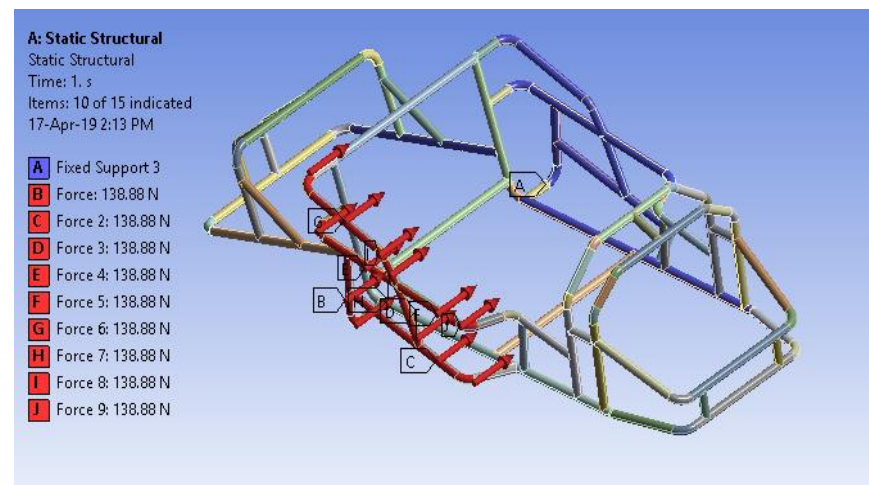

Figure 3. Boundary conditions for the chassis (Side Impact Test)

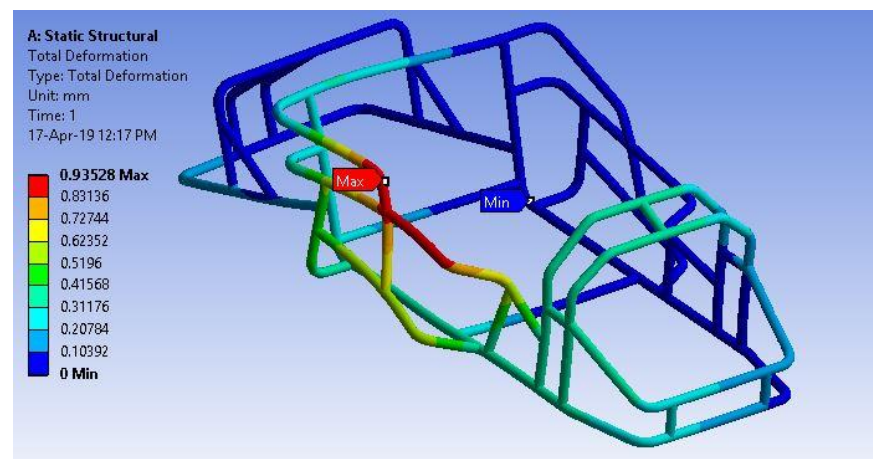

Figure 4. Total deformation

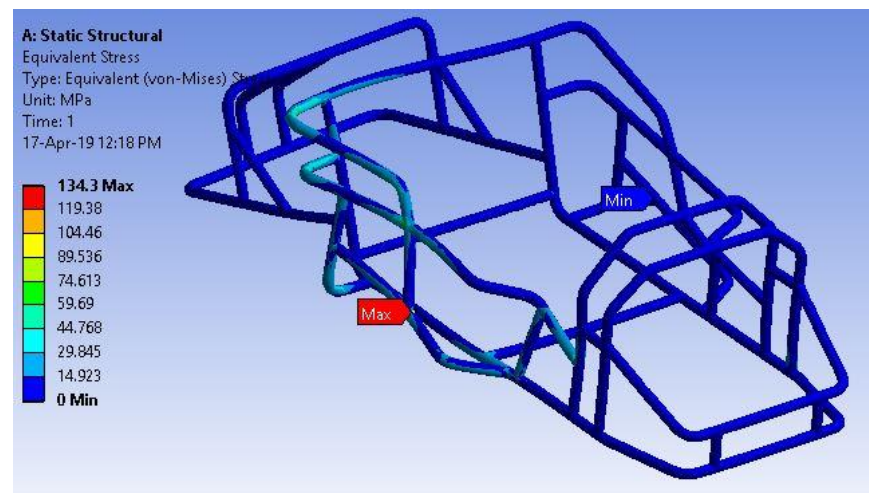

Figure 5. Equivalent stress

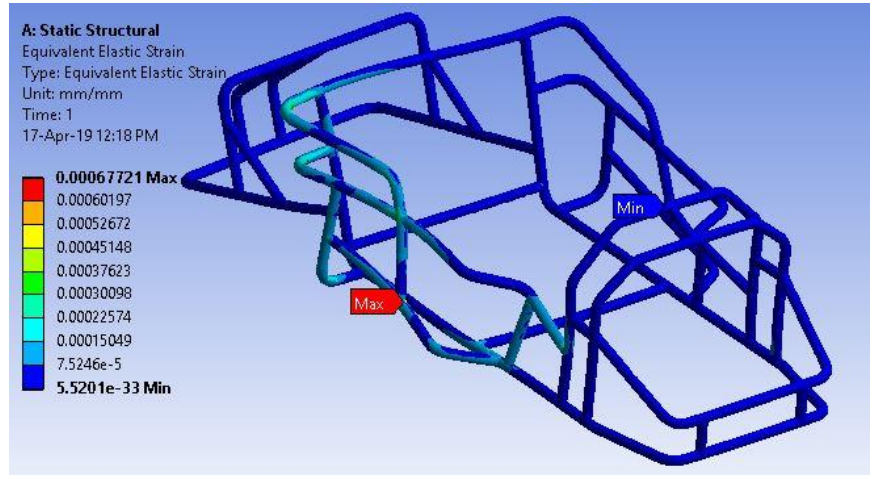

Figure 6. Elastic strain

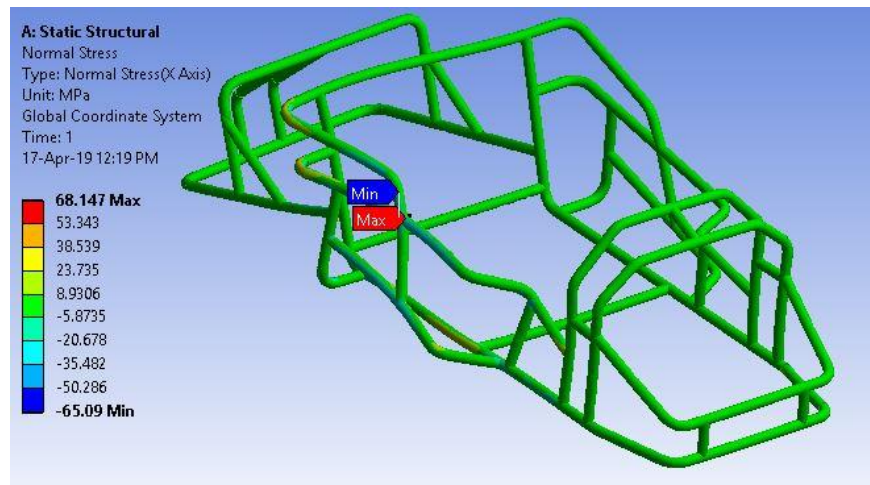

Figure 7. Normal stress

Figure 6 shows the maximum Elastic strain observed when the above load has been applied for the chassis. From Figure 6 , it is observed that the maximum elastic strain was found to be 0.00067 . Similarly, the maximum normal stress observed from Figure 7 shows a stress of 68.14 MPa. From these figures it is observed that the maximum stress and the corresponding strain was within the allowable limit and it is safe from design and analysis point of view.

\section{WORKING PRINCIPLE}

From Figure 8, it is observed that the pneumatic motor is connected to two tanks filled with compressed air. The compressed air is supplied at a high pressure to the motor which causes the vanes to rotate which in turn cause the shaft of the motor to rotate. The shaft is fitted with a sprocket that has a chain which in turn is fitted over a sprocket located on the drive shaft. Due to the rotary motion of the motor shaft, the chain rotates causing the driveshaft to rotate which produces the motion in the vehicle and the corresponding line diagram of working of air compressed vehicle is shown in Figure 8. The designed and developed air compressed vehicle was based on the principle of line diagram as shown in the Figure 8 .

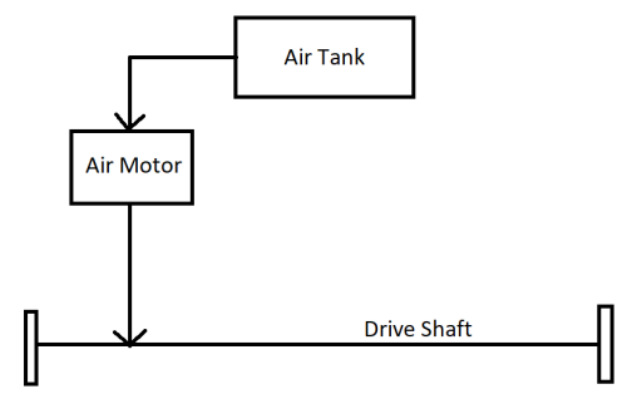

Figure 8. Basic principle of the compressed air vehicle 


\section{CONSTRUCTION: (COMPONENTS USED)}

In this section the different components required to assembly the compressed air vehicle have been discussed. The various components such as Air motor, compressed air tank, pressure regulator have been procured and then the chassis designed and the corresponding piping systems for connections have been assembled to check the performance of the air compressed vehicle.

\subsection{Air motor}

A 5.25 HP Gast 8AM-FRV-2B rotary vane pneumatic motor is used. It has a maximum speed of $2500 \mathrm{rpm}$. The maximum operating pressure is $6.8 \mathrm{bar}$. Maximum torque used is $21 \mathrm{~N}-\mathrm{m}$. Air consumption is $175 \mathrm{cfm}$ and the corresponding pneumatic motor is shown in Figure 9.

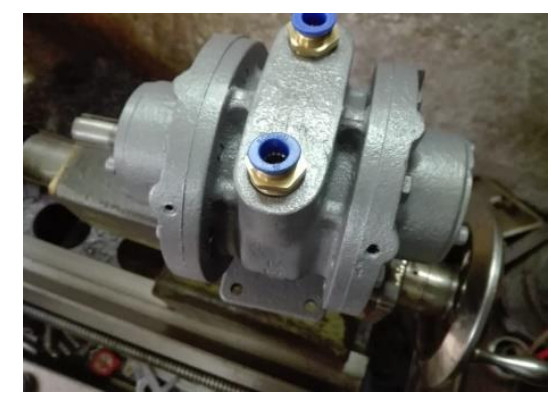

Figure 9. Pneumatic motor

\subsection{Compressed air tanks}

The air tanks are used to store compressed air. It has a capacity of 10 litres and the air is released at 150 bars. Each cylinder weighs around $15 \mathrm{~kg}$ and is as shown in Figure 10. The tanks were selected based on the following requirements: (a) Air consumption of the motor. (b) Desired runtime of the vehicle. (c) Weight of the tank with air. (d) Pressure of air in tank.

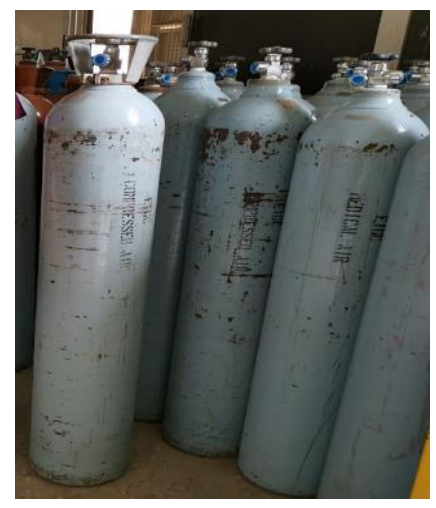

Figure 10. Air tanks

\subsection{Piping}

Pneumatic tubes of diameter $1 / 2$ inch are used for piping purposes. It's made from polyurethane (Refer Figure 11) and is more durable than PVC piping's. These tubes are necessary to maintain airtight connections between the motor and compressed air tank.

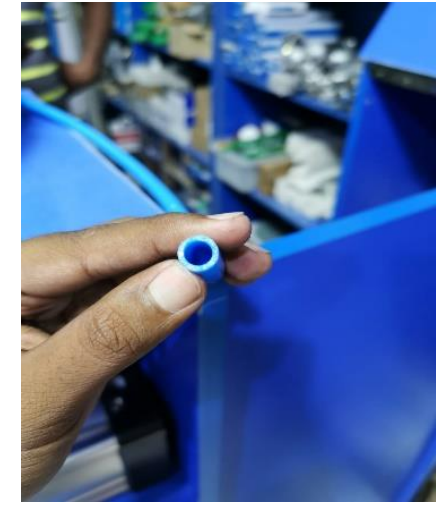

Figure 11. Piping

\subsection{Pressure regulator}

A pressure regulator shown in Figure 12 is used to decrease the pressure of the air being sent to the motor to 6.8 bars.

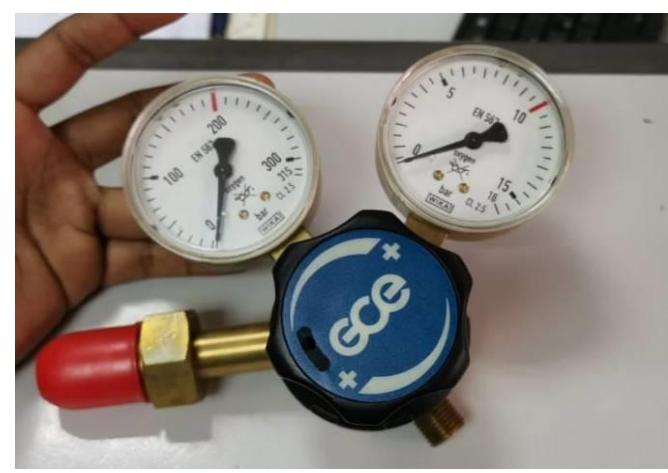

Figure 12. Pressure regulator

\subsection{Chassis}

The chassis being used is that of a sand buggy. It's made of mild steel bars with an outer diameter of $25 \mathrm{~mm}$ and thickness of $3.25 \mathrm{~mm}$ as shown in Figure 13 .

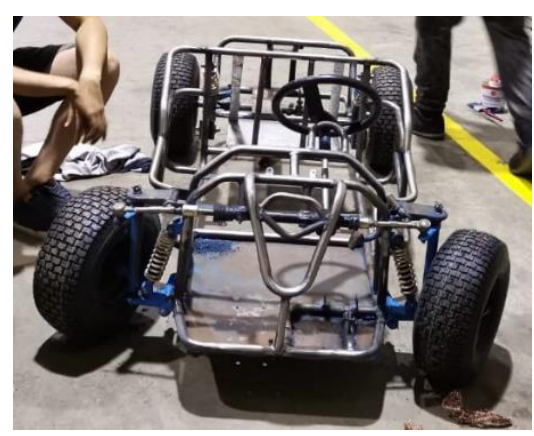

Figure 13. Chassis

\section{OPERATIONS USED AND FINAL PRODUCT}

Using lathe machine, the Machining of sprockets have been performed to fit the chain on the motor shaft. The removal of links in order to reduce the weight from $95 \mathrm{~kg}$ to $88 \mathrm{~kg}$ were done using cutting tool. Smoothening of those regions have been performed with the grinding tool and the base plate was welded for the air tanks using argon welding. 


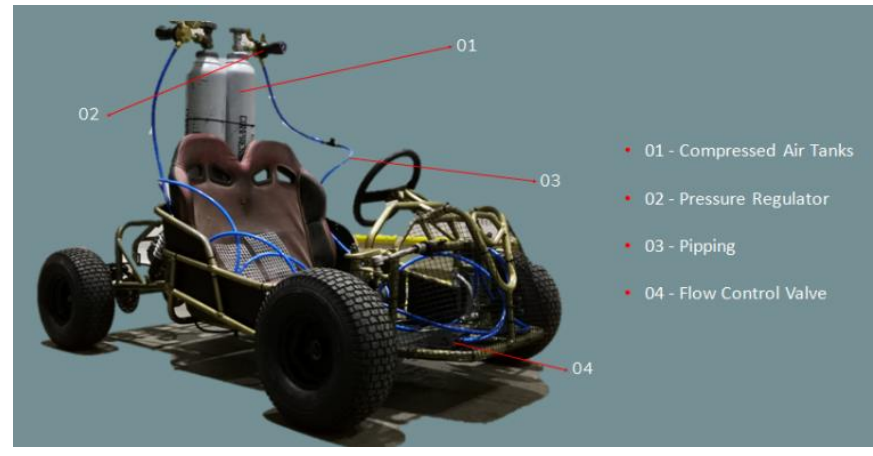

Figure 14. Final working product

The finished product (Refer Figure 14) was able to attain a top speed of $18 \mathrm{~km} / \mathrm{h}$ and an average speed of $10 \mathrm{~km} / \mathrm{h}$ when air was supplied at a pressure of 7 bars. The total run time was 4 minutes 30 seconds and the distance covered was $500 \mathrm{~m}$.

\section{RESULTS AND DISCUSSIONS}

The compressed air vehicle was tested on different pressure in order to obtain better results each time. A compressed air tank which is of 10 liter's is connected to the pneumatic rotary vane motor with the help of the polyurethane piping. The compressed air coming from the tank is controlled by the flow control valve. Once the desired pressure is set using a pressure regulator, the vehicle is set to move. The velocity of the running vehicle is obtained by the help of an accelerometer and the details of pressure, discharge, torque, power and velocity is as shown in Table 1.

Table 1. Test drive results of compressed air vehicle at different supply of air pressures

\begin{tabular}{cccccc}
\hline $\begin{array}{c}\text { S. } \\
\text { No }\end{array}$ & $\begin{array}{c}\text { Pressure } \\
(\mathbf{b a r})\end{array}$ & $\begin{array}{c}\text { Discharge } \\
(\mathbf{l} / \mathbf{s})\end{array}$ & $\begin{array}{c}\text { Torque } \\
(\mathbf{N m})\end{array}$ & $\begin{array}{c}\text { Power } \\
(\mathbf{k W})\end{array}$ & $\begin{array}{c}\text { Velocity } \\
(\mathbf{k m} / \mathbf{h})\end{array}$ \\
\hline 1 & 3 & 0.044 & 0.52 & 0.012 & 6 \\
2 & 4 & 0.055 & 1.176 & 0.033 & 7 \\
3 & 5 & 0.077 & 2.05 & 0.066 & 8 \\
4 & 6 & 0.078 & 4.41 & 0.214 & 12 \\
5 & 6.8 & 0.087 & 7.35 & 0.476 & 16 \\
6 & 7 & 0.11 & 9.7 & 0.708 & 18 \\
\hline
\end{tabular}

The discharge is calculated by the formula:

$$
\mathrm{Q}=\text { Volume/Time }
$$

where, Q is the Discharge.

The torque is calculated by using:

$$
\mathrm{T}=\mathrm{F}_{\mathrm{t}} \mathrm{x} \mathrm{R}
$$

where, $F_{t}$ is Tangential Force, $R$ is the Radius of the wheel and the power is calculated using,

$$
\mathrm{P}_{2}=2 \pi \mathrm{N}_{2} \mathrm{~T}
$$

where, $\mathrm{N}_{2}$ is the speed of the driveshaft, $\mathrm{T}$ is the torque.

The pneumatic rotary vane motor used has the capability to withstand 7 bar of air pressure. The experiments were conducted considering compressed air vehicle at different supply of air pressure to measure the velocity and then calculate discharge, torque and power. Using these results, it was understood that supplying more air pressure gives a higher velocity, discharge and torque but the run time of the vehicle is reduced as the pressure of the tank is increased. From the results obtained different graphs have been plotted.

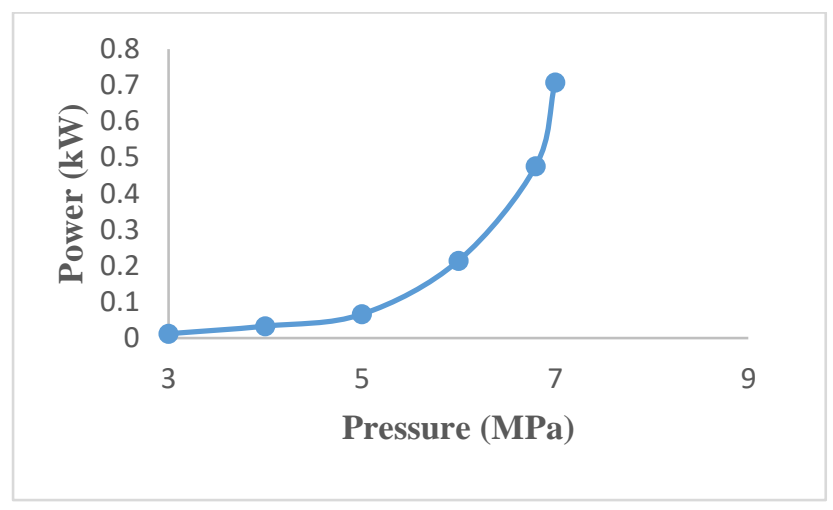

Figure 15. Pressure versus Power

Figure 15 shows the graph of pressure versus power. From this figure it is observed that as pressure of the compressed air increases the power of the vehicle increases. Thus, pressure is directly proportional to power.

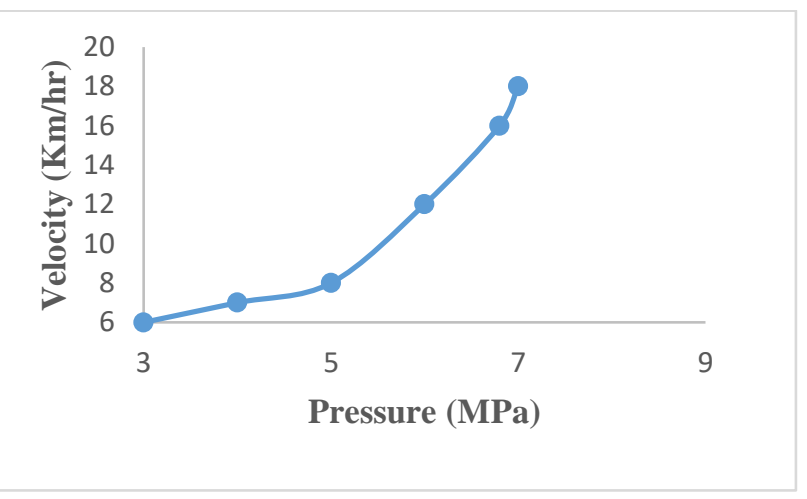

Figure 16. Pressure vs Velocity

Figure 16 shows the graph of pressure versus velocity. From this figure it is observed that as the pressure of the air coming from the compressed air tanks increases the velocity of the vehicle increases. Thus, pressure is directly proportional to velocity. From Figure 15 and Figure 16 it is observed that these curves are similar to parabolic rise and satisfies polytropic process. From the experiments it is also observed that the vehicle designed satisfies the above conditions.

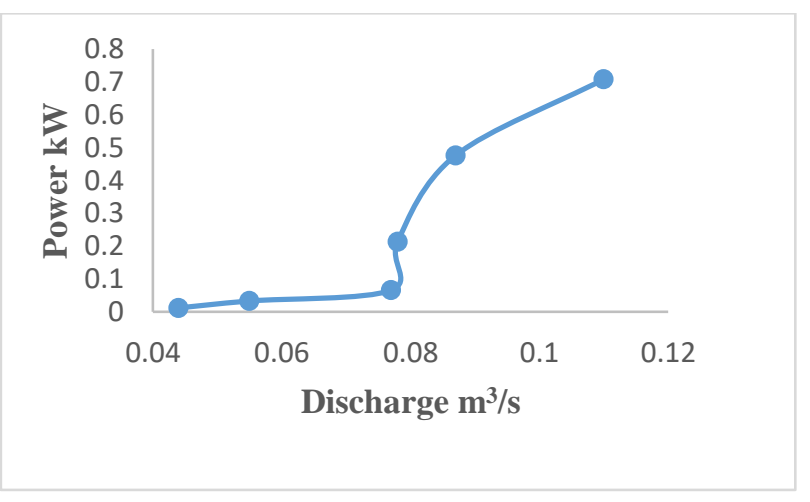

Figure 17. Discharge vs Power 
Figure 17 shows the graph of discharge versus power. From this figure it is observed that as discharge of the compressed air increases the power of the vehicle increases, thus discharge is directly proportional to power.

Figure 18 represents the graph of discharge versus velocity. From this figure it is observed that as discharge increases the velocity of the vehicle increases, thus discharge is directly proportional to velocity.

Figure 19 shows the graph of discharge versus torque. From this figure it is observed that as discharge increases the torque increases, thus discharge is directly proportional to torque. From Figure 17, Figure 18 and Figure 19 it is observed that the power, velocity and torque increase as the discharge of the vehicle increases and these curves behave in similar fashion as these graphs are plotted against discharge. From this graph it is also observed that for the discharge of less than $0.08 \mathrm{~m}^{3} / \mathrm{sec}$, the graphs of power, velocity and torque remains constant whereas it increases randomly after this particular point as more air is pushed into the cylinder.

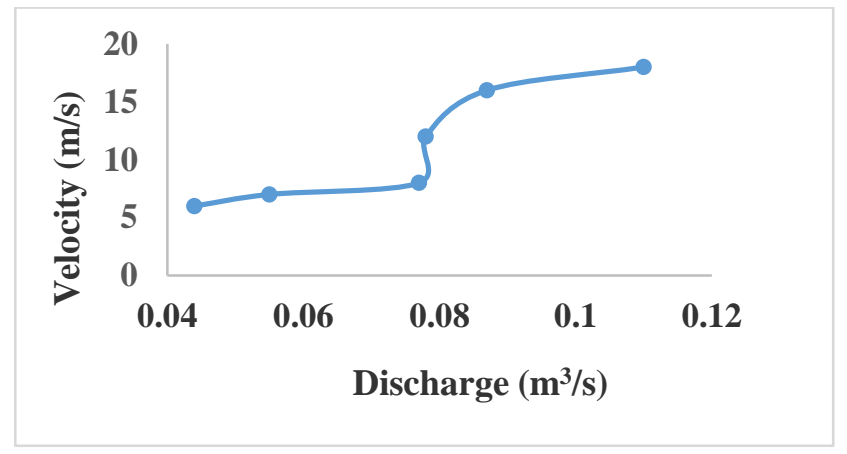

Figure 18. Discharge vs Velocity

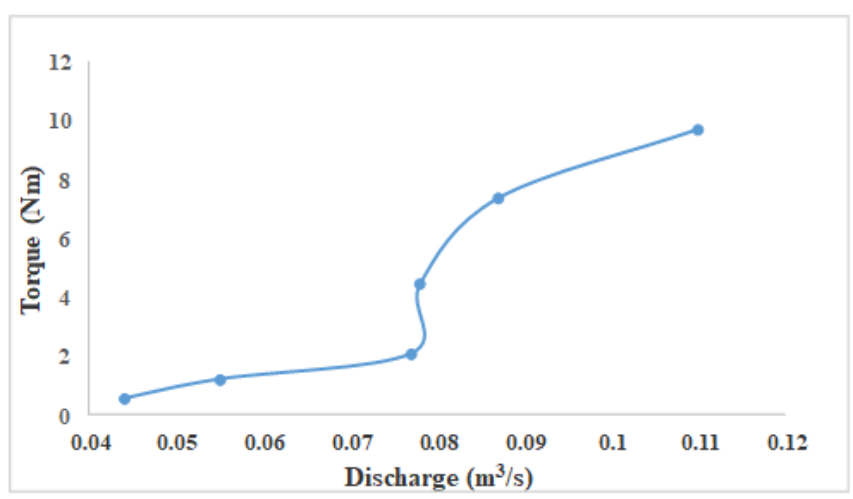

Figure 19. Discharge vs Torque

\section{CONCLUSIONS}

In this research work the design and fabrication of a compressed air vehicle have been performed. The analysis of different components of these vehicles have been performed. Based on these the following conclusions have been drawn. The main contributions in this research work are the design and fabrication of chassis and these designed chassis have been analyzed using ANSYS and various components have been assembled to test the air vehicle.

- $\quad$ The predicted velocity at the start of this research work was estimated to be around $35 \mathrm{~km} / \mathrm{hr}$ but was not able to achieve due to the unavailability of a more efficient pneumatic rotary vane motor.
- Structural analysis shows that the vehicle is stable and can withstand various load conditions and the factor of safety achieved was more than 1 .

- By increasing the capacity of the pneumatic motor (discharge) the velocity of the vehicle can be increased.

- By using a less dense and higher volume tank increases the output velocity of the vehicle and mileage.

- By varying the diameter of the output shaft sprocket, the velocity can be improved.

\section{REFERENCES}

[1] Papson, A., Creutzig, F., Schipper, L. (2010). Compressed air vehicles: Drive-cycle analysis of vehicle performance, environmental impacts, and economic costs. Transportation Research Record: Journal of the Transportation Research Board, 2191(1): 67-74. https://doi.org/10.3141/2191-09

[2] Kumar, S., Pradhan, P.K., Khan, Z.H., Kumar, A.B., Chaithanya, M. (2017). Design and developing of compressed air engine. International Research Journal of Engineering and Technology (IRJET), 4(5): 1468-1474.

[3] Ingle, A.H., Ambatkar, R., Badwaik, R., Pise, D., Dafare, A. (2016). Literature review paper on the compressed air vehicle with air motor. International Journal of Engineering Research \& Technology (IJERT), 4(30): 13.

[4] Pathak, S., Swetha, K., Sreedhar, V., Prabhakar, V.S.V. (2014). Compressed air vehicle: A review. International Journal of Mechanical and Production Engineering, 2(4): 9-14.

[5] Rixon, K.L., Shareef, M.V., Prajith, K.S., Sarath, K., Sreejith, S., Sreeraj, P. (2016). Fabrication of compressed air bike. International Research Journal of Engineering and Technology (IRJET), 3(1): 1863-1866.

[6] Singh, V. (2017). Compressed air engine. International Journal of Scientific and Research Publications, 7(7): 403-412.

[7] Allam, S., Zakaria, M. (2018). Experimental investigation of compresses air engine performance. International Journal of Engineering Inventions, 7(1): 13-20.

[8] Shetty, S., Sampath, S.S., Sharafat, M.M., Selvan, C.P.M. (2015). Estimation of power and mechanical efficiency of compressed air powered quad bike. American International Journal of Research in Science, Technology, Engineering \& Mathematics, 10(1): 85-93.

[9] Purushothaman, J., Sarathbabu, K., Arun, A. (2017). Design and development of compressed air engine. International Journal of Recent Engineering Research and Development (IJRERD), 2(8): 28-31.

[10] Tandan, G.K., Sahu, G., Sen, P.K., Sharma, R., Bohidar, S. (2015). A review paper on study and development of compressed air engine and their power source. International Journal of Science, Engineering and Technology Research (IJSETR), 4(11): 3770-3774.

[11] Verma, S.S. (2013). Latest developments of a compressed air vehicle: A status report. Global Journal of Researches in Engineering Automotive Engineering, 13(1): 15-23.

[12] Kumar, N.P., Shankar, N.V.S., Prasad Reddy, V.S.S.N. (2018). Performance of a compressed air engine. International Journal for Research in Applied Science 
and Engineering Technology (IJRASET), 6(5): 24562466. https://doi.org/10.22214/ijraset.2018.5403

[13] Devang, M., Sudhakar, S. (2016). A comprehensive review on compressed air powered engine. Renewable and Sustainable Energy Reviews, 70(C): 1119-1130. https://doi.org/10.1016/j.rser.2016.12.016

[14] Nayak, H.K., Goswani, D., Hablani, V. (2013). Technical review on study of compressed air vehicle (CAV). International Journal of Automobile Engineering Research \& Development (IJAERD), 3(1): 81-90.

[15] Manjunath, B.A., Binu, K.G., Santhosh, H., Kumar, R. (2017). Design and fabrication of air driven vehicle. Journal of Mechanical Engineering and Automation, 7(3): 112-115. https://doi.org/10.5923/j.jmea.20170704.05

[16] Wang, Y.W., You, J.J., Sung, C.K., Huang, C.Y. (2014). The applications of piston type compressed air engines on motor vehicles. Procedia Engineering, 79: 61-65. https://doi.org/10.1016/j.proeng.2014.06.311

[17] Simon, M. (2017). Pneumatic vehicle, research and design. Procedia Engineering, 181: 200-205. https://doi.org/10.1016/j.proeng.2017.02.370

[18] Sampath, S.S., Valladares, J., Pereira, C.M., Sreedharan, A.S., Sabin, N., Sachidananda, K.H. (2019). Design of a compressed air vehicle. International Journal of Innovative Technology and Exploring Research, 9(1): 4816-4823. https://doi.org/10.35940/ijitee.J9026.119119

\section{NOMENCLATURE}

$\begin{array}{lll}\text { Abbreviation } & \text { Description } & \text { Unit } \\ \mathrm{D}_{1} & \text { Diameter of the driving sprocket } & \mathrm{m} \\ \mathrm{D}_{2} & \text { Diameter of the driven sprocket } & \mathrm{m} \\ \mathrm{v} & \text { Velocity of the vehicle } & \mathrm{m} / \mathrm{s} \\ \mathrm{a} & \text { Acceleration of the vehicle } & \mathrm{m} / \mathrm{s}^{2} \\ \mathrm{~F} & \text { Force } & \mathrm{N} \\ \mathrm{m} & \text { Mass of the vehicle } & \mathrm{kg} \\ \mathrm{T} & \text { Torque } & \mathrm{Nm} \\ \mathrm{R} & \text { Wheel Radius } & \mathrm{m} \\ \mathrm{P}_{\text {out }} & \text { Output Power } & \mathrm{Watts} \\ \mathrm{P}_{\text {in }} & \text { Input Power } & \mathrm{Watts} \\ \mathrm{N}_{1} & \text { Speed of the driving sprocket } & \mathrm{RPM} \\ \mathrm{N}_{2} & \text { Speed of the driven sprocket } & \mathrm{RPM} \\ \eta & \text { Efficiency } & --- \\ \mathrm{g} & \text { Acceleration due to gravity } & \mathrm{m} / \mathrm{s}^{2} \\ \mathrm{~W} & \text { Weight of the vehicle } & \mathrm{kg}\end{array}$

